\title{
Odontogenic Myxoma of Maxilla
}

\author{
${ }^{1}$ Rashmi Maruti Hosalkar, ${ }^{2}$ Shilpa Patel, ${ }^{3}$ Jigna Pathak, ${ }^{4}$ Niharika Swain
}

\begin{abstract}
Odontogenic myxoma (OM) is a locally aggressive, benign, slowgrowing tumor arising from mesenchyme and/or odontogenic epithelium. It is the third most common odontogenic tumor predominantly affecting females and posterior mandible. Radiographically, OM demonstrates unilocular or multilocular, well or ill-defined radiolucency showing 'honeycomb', 'soap-bubble' or 'tennis-racket' pattern with cortical expansion and tooth displacement. Histologically, OM shows loosely arranged stellate or spindle-shaped cells interspersed in myxoid matrix. Various treatment modalities, such as wide excision, enucleation and curettage, curettage with/without electrical or chemical cautery, enbloc resection and wide resection with/without immediate grafting can be considered based on the extent of the lesion. Here, we present a case of a 17-year-old female, with $\mathrm{OM}$ in the left maxilla and the maxillary sinus.
\end{abstract}

Keywords: Odontogenic myxoma, Maxilla, Myxoid, Reticulin. How to cite this article: Hosalkar RM, Patel S, Pathak J, Swain N. Odontogenic Myxoma of Maxilla. J Contemp Dent 2015;5(1):27-30.

Source of support: Nil

Conflict of interest: None

\section{INTRODUCTION}

In 2005, World Health Organization (WHO) has classified odontogenic myxoma $(\mathrm{OM})$ as a tumor arising from mesenchyme and/or odontogenic ectomesenchyme with/without odontogenic epithelium. ${ }^{1}$ It is believed to arise from primitive mesenchymal portion of tooth germ. ${ }^{2} \mathrm{OM}$ is a benign, slow growing but locally aggressive neoplasm affecting jaw bones that accounts for about 3 to $6 \%$ of all odontogenic tumors, affecting females more than males. It is the third most common odontogenic tumor. While OMs predominantly involve the mandible, maxillary tumors are said to be more aggressive. Majority of lesions that are without pain reach a large size and cause displacement of the teeth and asymmetry of the mandible or maxilla prior to discovery. Certain lesions spread with progressive pain through the maxillary sinus and nasal

\footnotetext{
${ }^{1}$ Postgraduate Student, ${ }^{2}$ Professor and Head

${ }^{3}$ Professor, ${ }^{4}$ Lecturer

${ }^{1-4}$ Department of Oral Pathology and Microbiology, MGM Dental College and Hospital, Navi Mumbai, Maharashtra, India
}

Corresponding Author: Rashmi Maruti Hosalkar, Postgraduate Student, Department of Oral Pathology and Microbiology, MGM Dental College and Hospital, Navi Mumbai, Maharashtra, India Phone: 09029985467, e-mail: drrashmi009@gmail.com cavity, and severe cases result in exophthalmos, nasal obstruction and neurological disturbance. ${ }^{1}$

Here, we present a case of a 17-year-old female, with $\mathrm{OM}$ in the left maxilla and maxillary sinus.

\section{CASE REPORT}

A 17-year-old female reported to the department with complain of swelling on left upper region of the jaw since 3 months, which gradually increased to the current size. On extraoral clinical examination, a diffuse swelling was seen in left maxillary region obliterating the nasolabial fold (Fig. 1). Intraoral examination revealed a diffused, painless swelling present in 21 to 24 region, obliterating the buccal vestibule which appeared to be firm in consistency (Fig. 2). Radiological examination by computed tomography showed well defined, mixed radiopaqueradiolucent swelling causing bicortical expansion of left maxillary region involving the anterior wall of maxillary sinus and extending into maxillary antrum (Fig. 3). Orthopantomograph revealed ill-defined multilocular mixed radiopaque-radiolucent lesion with fine bony trabeculae within its interior structure (Fig. 4). Provisional diagnosis of ameloblastoma, ameloblastic fibroma, ameloblastic fibro-odontoma, odontogenic fibroma, odontogenic myxoma, central giant cell granuloma and fibro-osseous lesion was made based on clinicoradiographic features. The lesion was surgically excised under local anesthesia with informed consent. Macroscopically, the lesion appeared to be well defined, lobulated and with a gelatinous texture (Fig. 5). Microscopically, the cut sections demonstrated abundant loose myxoid stroma

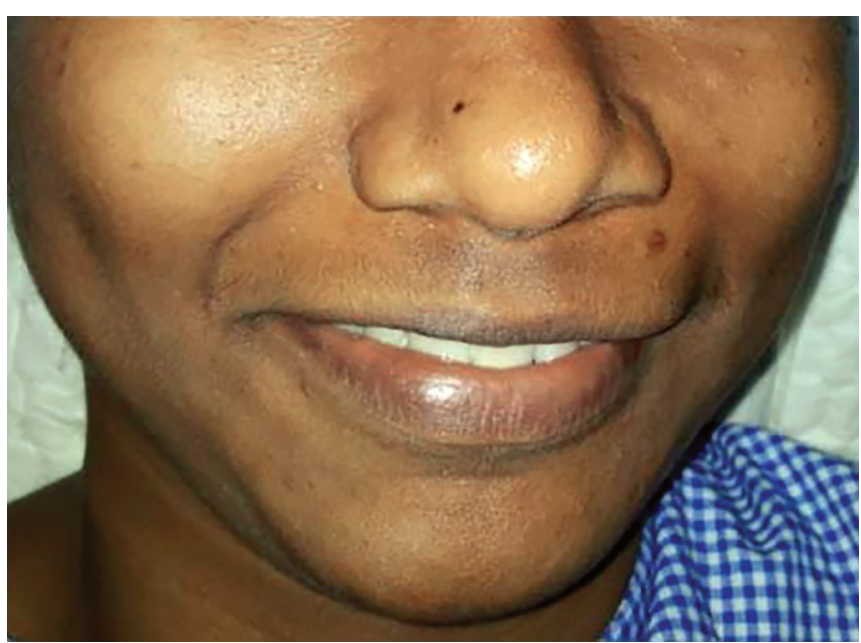

Fig. 1: Extraoral photograph of the patient 
with few collagen fibrils. Stellate-shaped cells with anastomising processes were seen scattered in haphazard manner throughout the myxoid ground substance (Figs 6 to 8). The fibrils stained positive with silver impregnation and were proved to be reticulin (Fig. 9).

\section{DISCUSSION}

Myxoma, was the term given by Virchow in 1871 when he first observed that tumors showed histological features similar to umbilical mucinous tissue. ${ }^{3}$ In 1948, Scout $^{4}$ established a diagnostic criterion for myxoma stating that it is a true neoplasm formed exclusively from undifferentiated star-shaped cells, in a loose mucoid stroma, and does not metastasize. Following which, myxomas are referred to as an uncommon and locally infiltrative benign connective tissue tumor that develops both within bone and soft tissue. ${ }^{5}$ Myxomas can be found in various sites in the body including the skin and subcutaneous tissue, heart (mainly in the left atrium) and in head

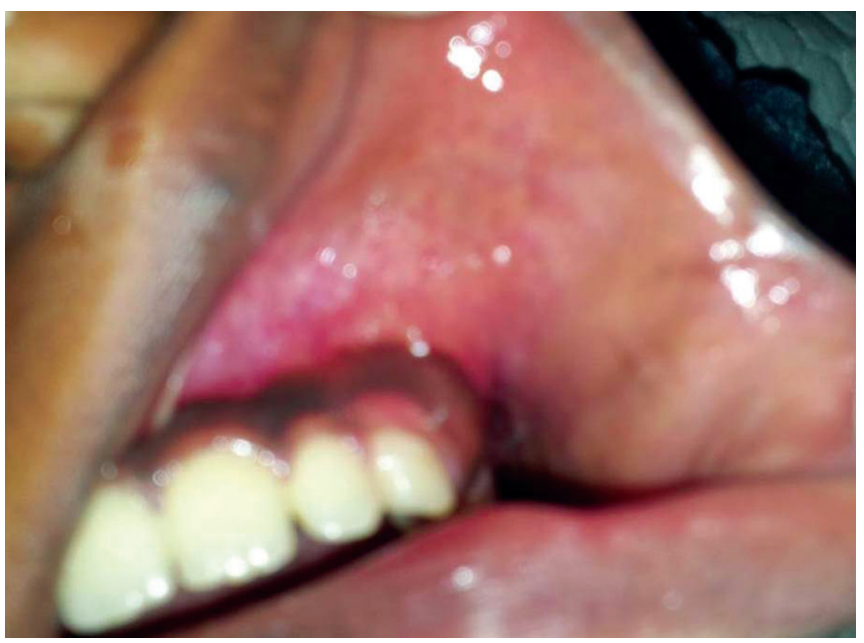

Fig. 2: Intraoral photograph of the patient

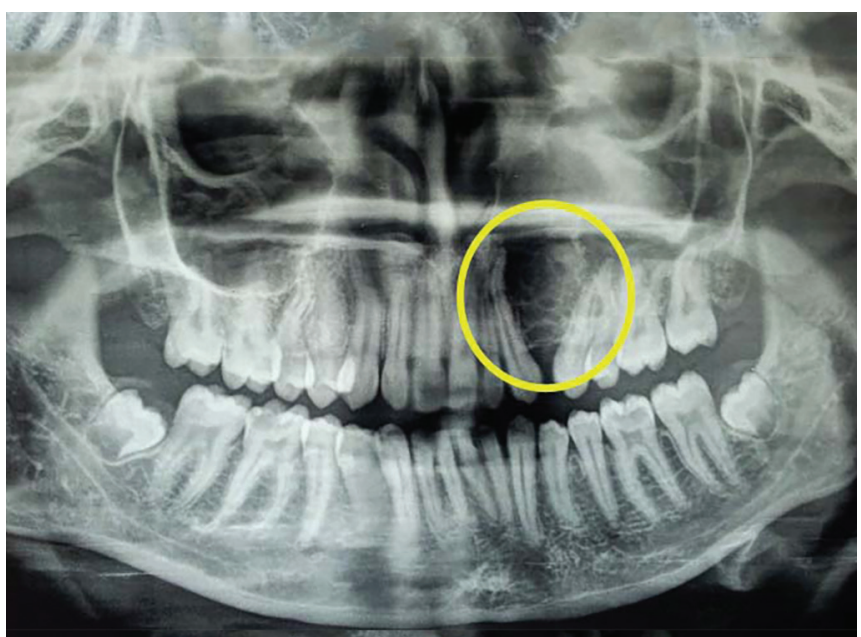

Fig. 4: Orthopantomograph showing diffuse mixed radiopaqueradiolucent lesion on the left side of maxilla in 23 and 24 region along with displacement of teeth and neck. Myxomas occur rarely in the head and neck region. These are further classified into two types: those derived from facial bones which are further subdivided into true osteogenic myxoma and odontogenic myxoma and those derived from facial soft tissue like perioral soft tissue, parotid gland, ear or larynx. ${ }^{6}$ In 1947, Thoma and Goldman were first to describe OM occurring in maxilla.? It is a nonencapsulated benign tumor of jaw that can be classified as one arising from bone and one arising from soft tissue. It is third most common among odontogenic tumors following ameloblastoma and odontome. ${ }^{1}$

The histopathogenesis of myxomatous component of odontogenic along with nonodontogenic origin of $\mathrm{OM}$ is still a subject of debate and includes myxoid degeneration which can occur in an originally nonmyxoid tumor. Due to the microscopic resemblance of OM to the mesenchymal portion of a developing tooth, such as dental follicle and papilla and other odontogenic tumors, such as ameloblastic fibroma, the origin of

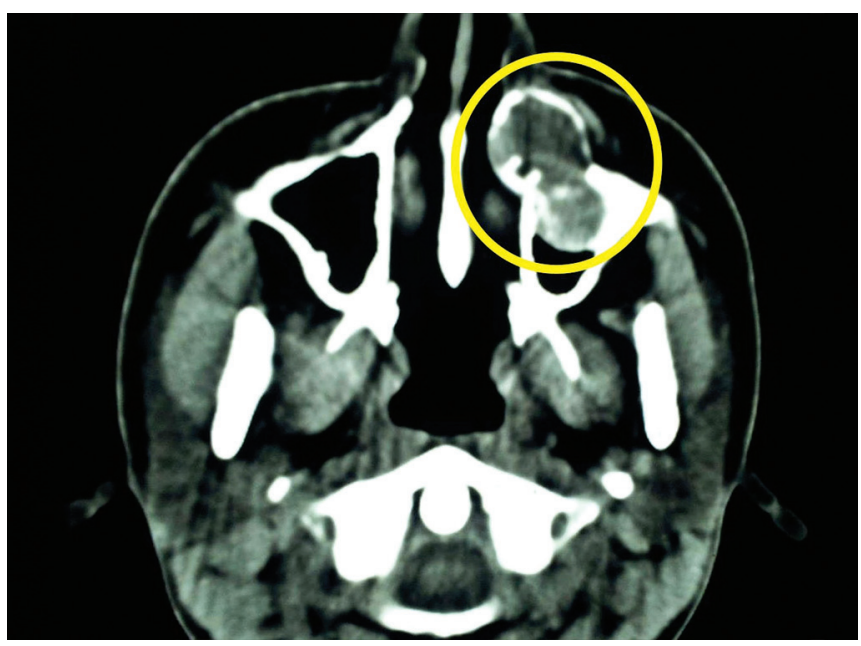

Fig. 3: Computer tomography showing mixed radiopaqueradiolucent lesion on the left side of maxilla and also involving the maxillary sinus

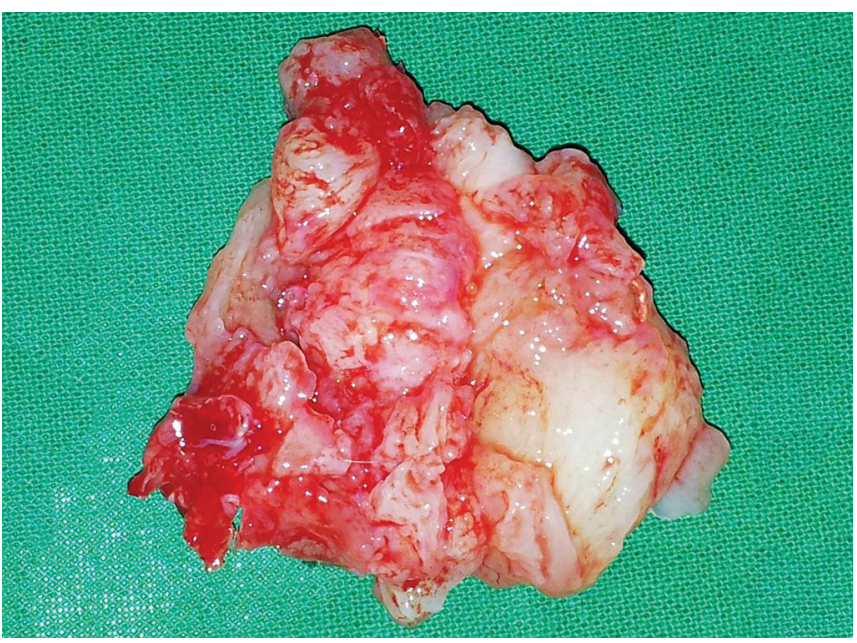

Fig. 5: Photograph of the gross specimen of excised lesion 
OMs from odontogenic ectomesenchyme was put forth. Another hypothesis in regards to origin is altered/primitive fibroblasts or myofibroblasts producing excess of mucopolysaccharides (proteoglycans) and which was commonly incapable of forming mature collagen even if some cells retained the capacity. The amount and types of proteoglycan OM contains, vary from that in the mesenchymal tissues. In some studies, authors have found that hyaluronic acid concentration within $\mathrm{OM}$ is four times higher than those of other glycosaminoglycans, such as chondroitin sulphate. This is inverse to what was found in mesenchymal tissues from dental pulp, gingiva and periodontal ligament. Origin from periodontal tissue has also been suggested. . $^{8}$

The overall prevalence of OM is between 0.04 and 3.7\% but, in Asia, Europe and America, the relative frequencies are between 0.5 and $17.7 \%$. OM occurs more commonly in 2 nd to 4 th decades of life with high female preponderance. ${ }^{10}$ The present case describes the lesion occurring

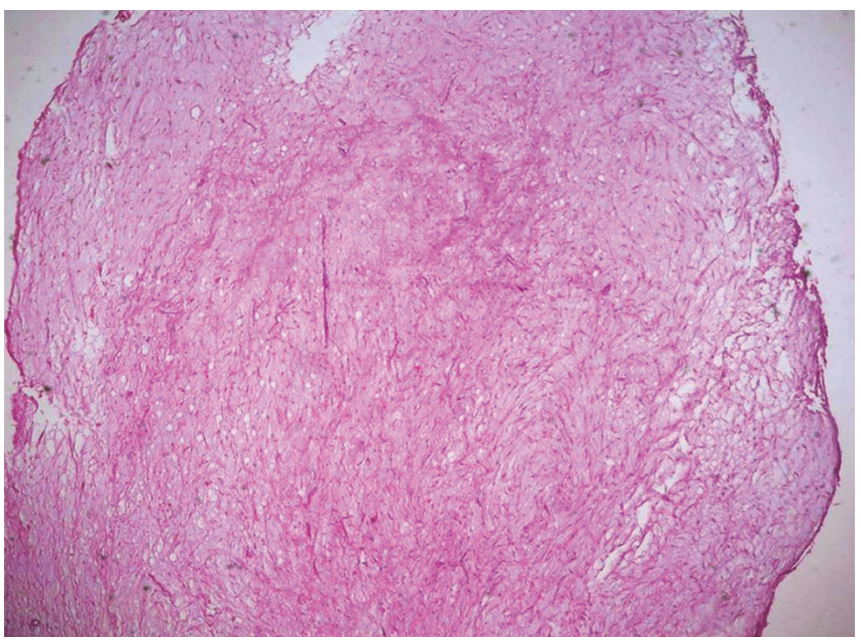

Fig. 6: Photomicrograph of soft-tissue section showing abundant loose myxoid stroma with few collagen fibrils (hematoxylin \& eosin stain: $40 \times$ magnification)

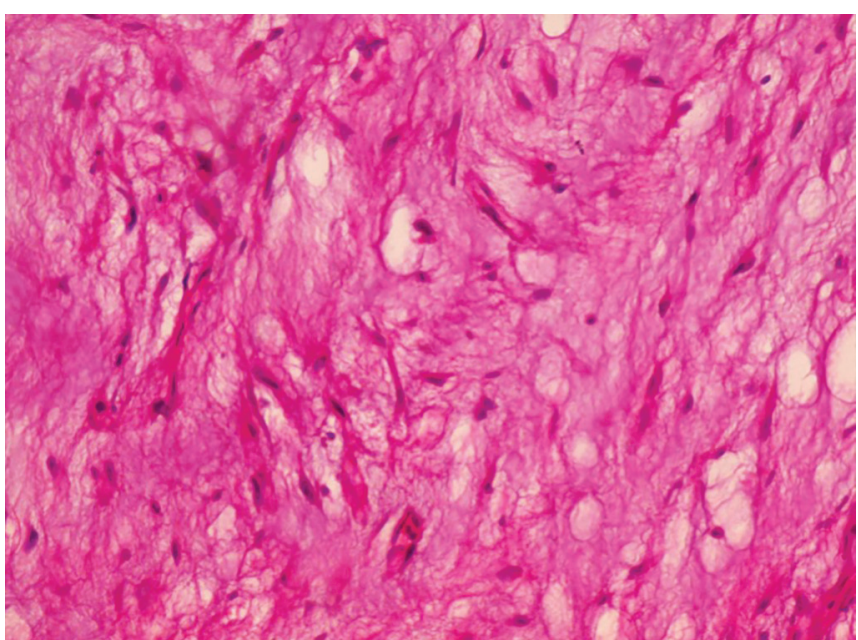

Fig. 8: Photomicrograph of soft-tissue section showing spindleand stellate-shaped cells interspersed in myxoid ground substance (hematoxylin \& eosin stain: $400 \times$ magnification) in a 17-year-old female patient. Majority of OM occur in the mandible and is mostly seen in posterior region (premolar-molar). ${ }^{711}$ According to Reichart and Philipsen, mandibular myxomas accounted for $66.4 \%$, with $33.6 \%$ in the maxilla, whereas $65.1 \%$ of the mandibular cases were located in the molar and premolar areas, $73.8 \%$ cases were seen in the same areas of the maxilla. ${ }^{11} \mathrm{Kaffe}$ et al reviewed 164 cases of which 55 were associated with maxilla. ${ }^{12}$

Noffke et al also found that 17 cases of 30 OMs were located in maxilla. In present case, the lesion occurred in the anterior region extending upto the premolar area. According to Barros et al, the radiologic features of myxomas depend on the stage of evolution of the tumor, as early lesions produce osteoporotic-like areas, later forming larger areas of osteolysis, with cortical bone expansion and infiltration of adjacent soft tissues. Radiologically, OM can appear as a unilocular or multilocular, well or ill-defined radiolucency showing 'honeycomb',

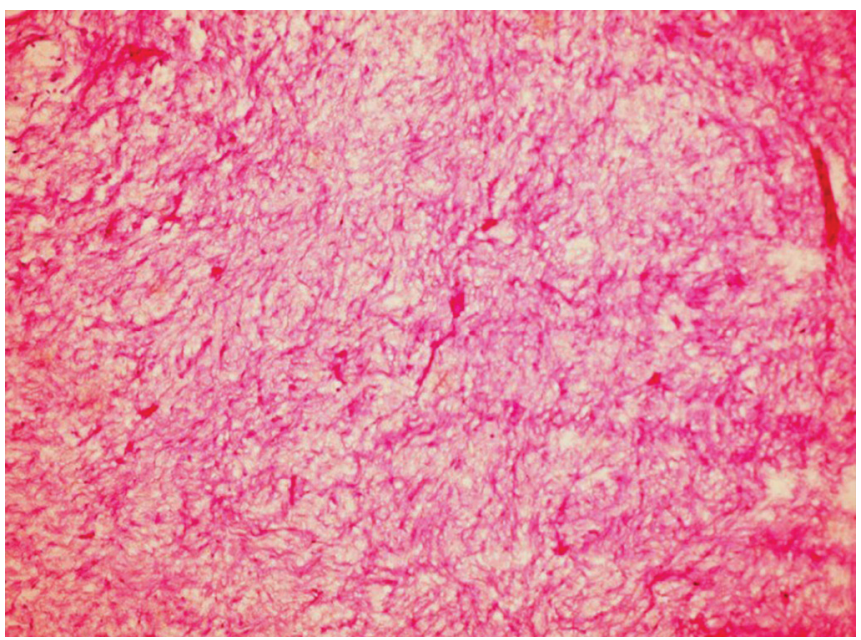

Fig. 7: Photomicrograph of soft-tissue section showing abundant loose myxoid stroma with few collagen fibrils (hematoxylin \& eosin stain: $100 \times$ magnification)

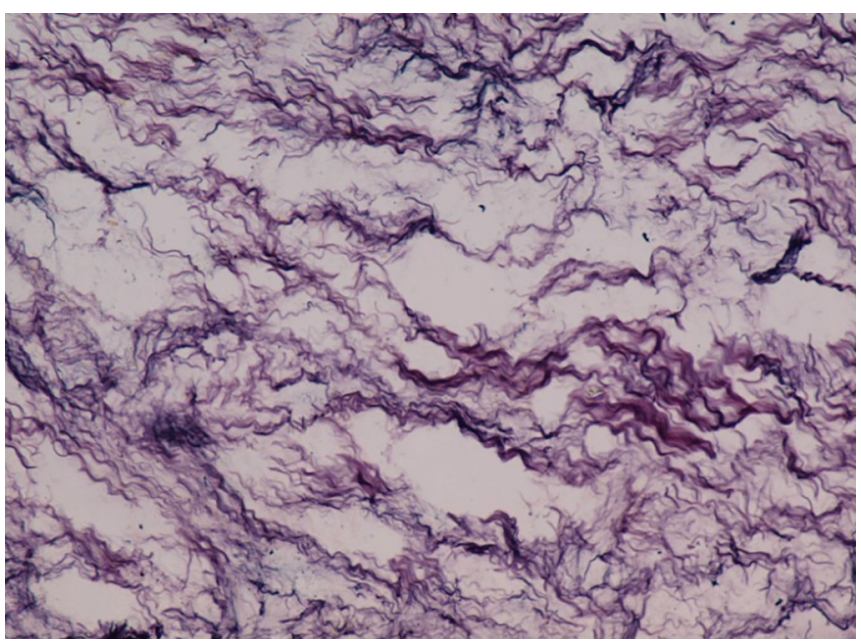

Fig. 9: Photomicrograph of reticulin fibers (reticulin stain: $100 \times$ magnification) 
'soap-bubble' or 'tennis-racket' pattern with cortical expansion and tooth displacement. ${ }^{14}$ Zhang et al in their study described six different types on basis of the conventional radiographs as type I- unilocular; type II-multilocular (including honeycomb, soap bubble and tennis racket patterns); type III-involvement of local alveolar bone; type IV-features of type III and involvement of the maxillary sinus; type $\mathrm{V}$-osteolytic destruction and type VI-a mix of osteolytic destruction and osteogenesis. ${ }^{15}$ Our case shows type IV radiographic pattern which has been observed in $22 \%$ of the cases in previous study. ${ }^{15}$

Histologically, OM shows anastomosing processes of spindle, wedge or stellate-shaped cells lying loosely in an abundant background of acid mucopolysaccharide. Islands of inactive odontogenic epithelium may or may not be observed. ${ }^{16}$ Sections stained with special stains, such as reticulin methods, showed that the extracellular matrix contained abundant acid and neutral mucopolysaccharides as well as reticulin fibers. Other stains that can be used are alcian blue and periodic acid schiff. The histological features were in accordance with the literature. A special stain, such as reticulin, was also positive. Histological differential diagnosis considered for the lesion was odontogenic fibroma, oral focal mucinosis. Odontogenic fibroma is more fibrous, is encapsulated and lacks the stellate-shaped cells typical of myxoma while oral focal mucinosis lacks reticulin fibers.

A number of treatment modalities can be considered for OM depending upon the extent of the lesion and includes wide excision, enucleation and curettage, curettage with/without electrical or chemical cautery, en bloc resection and wide resection with/without immediate grafting. ${ }^{18}$ The lesion was surgically excised with patients consent in our case. The overall recurrence rate ranges from 10 to $33 \%{ }^{11}$ Noffeke et al suggested that the higher recurrence rate was related to the tumor spillage during the operative procedure due to the gelationous consistency and poorly defined margins. ${ }^{13}$ As the recurrence rate is high in $\mathrm{OM}$, it is a must that the patient should be followed for 5 years to establish a diseased free state. ${ }^{19}$ However, our patient was lost to follow-up postoperatively.

\section{CONCLUSION}

Histopathological diagnosis of OM becomes a necessity as it is very difficult for a diagnosis of OM to be made based on clinicoradiological parameters. At the same time, recurrence rate of $\mathrm{OM}$ is high and mandates a follow-up in all the cases. The present report attempts to throw a light for proper understanding and knowledge on OM.

\section{REFERENCES}

1. Barnes L, Eveson JW, Reichert P, et al. World Health Oraganisation Classification of Tumours. Pathology and Genetics of Head and Neck Tumours. Lyon: IARC Press; 2005. p. 1-430.

2. White DK, Chen SY, Mohnac AM and Miller AS. Odontogenic myxoma: a clinical and ultrastructural study. OOO 1975;39(6):901-917.

3. Virchow R. Die cellular pathologie in ihrer beegrundung auf physiologische and pathologische Gewebelehre. Berlin, Germany, Verlag von August Hirschwald 1871;563.

4. Stout AP. Myxoma, the tumor of primitive mesenchyme. Ann Surg 1948;127(4):706-719.

5. de Melo GM, et al. Myxoma of cervical soft tissue: case report and literature review. Int Arch Otorhinolaryngol 2008;12(4): 587-590.

6. Munjal M, et al. Odontogenic myxoma of the maxilla: a clinical case report and review of literature. Otolaryngology Online Journal 2013;3(2):ISSN:2250-0359a.

7. Chrcanovic BR, Figueiredo do Amaral MB, Marigo HA, Freire-Maia B. An expanded odontogenic myxoma in maxilla. Stomatologija, Baltic Dental and Maxillofac J 2010; 12(4):122-128.

8. Mehendiratta M. The histological spectrum of myxoma, myxofibroma/fibromyxoma and odontogenic fibroma: a chicken and egg situation. IOSRJDMS 2012;1(1):3-5.

9. Taylor AM. New findings and controversies in odontogenic tumors. Med Oral Pathol Oral Cir Bucal 2008 Sep 1;13(9):E555558.

10. Simon ENM, Merkx MAW, Vuhahula E, Ngassapa D, Stoelinga P. Odontogenic myxomas: a clinicopathological study of 33 cases. Int J Oral Maxillofac Surg 2004;33(4):333-337.

11. Reichart PA, Philipsen HP. Odontogenic tumors and allied lesions. Quintessence; Chapter 20. Odontogenic myxomas or myxofibroma 2004. p. 189-196.

12. Kaffe I, Naor H, Buchner A. Clinical and radiological features of odontogenic myxoma of the jaws. Dentomaxillofac Radiol 1997;26(5):299-303.

13. Noffke CE, Raubenheimer EJ, Chabikuli NJ, Bouckaert MM. Odontogenic myxoma: review of the literature and report of 30 cases from South Africa. Oral Surg Oral Med Oral Pathol Oral Radiol Endod 2007 July;104(1):101-109.

14. Barros RE, Dominguez FV, Cabrini RL. Myxoma of the jaws. Oral Surg Oral Med Oral Pathol 1969;27(2):225-235.

15. Zhang J, Wang H, He X, Niu Y, Li X. Radiographic examination of 41 cases of odontogenic myxomas on the basis of conventional radiographs. Dentomaxillofac Radiol 2007 Mar;36(3):160-167.

16. Rajendran R, Sivapathasundaram B. Shafer's Textbook of Oral Pathology. 6th ed. New Delhi: Elsevier; 2009. p. 148.

17. James L, Shetty A, Jaypal N, Okade D. Oral soft tissue myxomas. J Ind Aca Oral Med Radiol 2012;24(2):152-154.

18. Brannon RB. Central odontogenic fibroma, myxoma (odontogenic myxoma, fibro-myxoma) and central odontogenic granular cell tumor. Oral Maxillofac Surg Clin North Am 2004;16(3):359-374.

19. Thomas P, Suresh Babu G, Mishra C, Anusha RL, Shetty S. Odontogenic myxoma: a report of two cases with review of literature. JIAOMR 2011 Apr-June;23(2):143-146. 